\title{
RESEARCH PAPER \\ EXERCISE PARTICIPATION AND DIET MONITORING IN PURSUIT OF HEALTHY AGING AMONG THE UNIVERSITY STAFF MEMBERS
}

\author{
J. B. Gbenga ${ }^{1}$ and J. F. Babalola ${ }^{2}$ \\ ${ }^{1}$ Department of Sports Science, Afe Babalola University, Ado-Ekiti, Nigeria \\ Dredeemed4christ@gmail.com \\ ${ }^{2}$ Department of Human Kinetics and Health Education, University of Ibadan, Nigeria \\ Dr_babasonfun@yahoo.com
}

\begin{abstract}
This study examined the level of exercise participation and diet monitoring in pursuit of healthy aging. Descriptive survey research design and self-structured questionnaire was used to elicit information from the respondents. Proportionate stratified and simple random sampling techniques were used to select two hundred and nineteen (219) respondents $(60.7 \%$ male and $33.2 \%$ female) who formed the sample size for the study. Statistical analysis of mean, standard deviation, percent counts, frequency, chi-square and spearman rank correlation coefficient were carried out. Results showed that university staff members had significant level of exercise participation and proper diet monitoring in pursuit of healthy aging $\left(X^{2}=204.05, p=.000\right.$; $\left.X^{2}=235.16, p=.000\right)$. Exercise participation and diet monitoring in pursuit of healthy aging had very weak positive relationship $(r=0.132, p=.000)$. The study revealed that it is possible to focus more on exercise participation and neglect diet monitoring or vice versa. Exercise participation and diet monitoring are closely related to living a healthy lifestyle with satisfactory life-work growing productivity level and both should be given adequate attention.
\end{abstract}

Keywords: Exercise participation, diet monitoring, healthy aging

\section{INTRODUCTION}

Aging well may sound self-explanatory, but the term encompasses many aspects of health including eating right, moderate exercise, maintaining mental acuity and healthy social circles (Jaiyesimi, 2009). Eating a nutritious diet, maintaining a healthy body weight, and a physically active lifestyle are key influential factors in helping individuals avoid the physical and mental deteriorations associated with aging. High physical inactivity rates have been reported in many industrialized countries, as well as in a growing number of developing nations (World Health Organization, 2006). It is difficult to estimate trends of physical inactivity in sub-Saharan Africa due to the dearth of research proven data. In a systematic review of the prevalence of physical activity in Ghana and Nigeria, 25 to $57 \%$ of Nigerians were estimated to be physically inactive while 
$20 \%$ and $14 \%$ approximately of the Ghanaian population were found to be overweight and obese though data from various studies were considered to be limited, poorly reported and not easily comparable (Abubakari and Bhopal, 2008). The socio-cultural climate of West African urban setting, characterized by affluence of comfort, has led to increase in sedentary lifestyle and related diseases (Abubakari et al. 2009; Frank et. al.,2012).

Physical activity levels among older adults, as well as their younger counterparts, typically fall well below the 150 minutes or more of weekly moderate-intensity physical activity (i.e., akin to brisk walking) currently recommended by a growing number of nations to achieve optimal health benefits (U.S. Department of Health and Human Services, 2008). Moderate forms of physical activity that are particularly attractive to midlife and older adults (e.g., walking) have been demonstrated to positively impact health (Hakim et al., 1998). Monteiro et al, (2003) described walking as an inexpensive form of physical activity which is common and accessible and as well forms important component of total physical activity in adult populations.

According to Jeste et al., (2010), approximately one third of older adults globally are aging successfully based on objective criteria. However, a great number of older adults perceive themselves as aging successfully despite the presence of illness and disability. Of the most common causes of death of adults aged 65 years and older in the United States, five out of eight have a known nutritional influence (Brian et al., 2008.) Almost $80 \%$ of older adults have one chronic condition, and half of all older adults have two or more (National Centre for Chronic Disease Prevention and Health Promotion, 2011). Preventing chronic diseases and reducing associated complications call for essential strategy for keeping older adults healthy, independent, and efficient. Nutrition, physical activity and exercise are the major determinants of successful aging, even though health status has multiple contributing factors. In addition, food is not only critical to one's physiological well-being but also contributes to social, cultural, and psychological quality of life.

\section{MATERIALS AND METHOD}

The setting for this study was the ancient city of Ibadan, Nigeria. The study examined the level of exercise participation and diet monitoring in pursuit of healthy aging among the University staff members. Descriptive survey research design was used for the study. The simple random (Fishbowl) method and proportionate stratified random sampling techniques were adopted as the sampling techniques for the study. The simple random (fishbowl) methodwas used to select the four faculties for the study. The proportionate stratified random sampling technique was used to select $20 \%$ of the respondents from each faculty. A total of 219 members of academic staff and non-academic staff participated in the survey (133 male and 86 female). A selfstructured questionnaire was used to collect information on the level of exercise participation and diet monitoring in pursuit of healthy aging among the university staff members. The instrument was validated through construct and content validity. Reliability of the instrument ( $\mathrm{r}=0.82$ correlation coefficient) was done through a pilot study of test re-test method on the sample of neutral population outside the study area. The instrument was administered personally by the researcher and a research assistant.

Frequency and percent counts were used to summarize the data collected. Chi-square goodness of fit $\left(X^{2}\right)$ was used to test the level of association while spearman rank correlation coefficient was used to test the level of relationship. The significance level was set at 0.05 .

\section{RESULTS AND DISCUSSION}

The study examined exercise participation and diet monitoring in pursuit of healthy aging 
Table-1: Demography of respondents

\begin{tabular}{|c|c|c|}
\hline $\begin{array}{l}\text { Subgroup } \\
\text { Gender }\end{array}$ & Frequency & Percentages $(\%)$ \\
\hline Male & 133 & 60.7 \\
\hline Female & 86 & 39.3 \\
\hline \multicolumn{3}{|l|}{ Age } \\
\hline $30-34$ & 44 & 20.0 \\
\hline $35-39$ & 46 & 21.0 \\
\hline $40-44$ & 37 & 16.9 \\
\hline $45-49$ & 31 & 14.2 \\
\hline $50-54$ & 35 & 16.0 \\
\hline 55 and above & 26 & 11.9 \\
\hline \multicolumn{3}{|l|}{ Marital status } \\
\hline Single & 32 & 14.5 \\
\hline Married & 178 & 81.3 \\
\hline Widowed & 8 & 3.7 \\
\hline Divorced & 1 & 0.5 \\
\hline \multicolumn{3}{|l|}{ Nature of job } \\
\hline Teaching & 94 & 42.9 \\
\hline Non-teaching & 125 & 57.1 \\
\hline \multicolumn{3}{|l|}{ Faculty } \\
\hline Education & 57 & 26.0 \\
\hline Science & 77 & 35.2 \\
\hline Social Science & 31 & 14.2 \\
\hline Agriculture & 54 & 24.6 \\
\hline \multicolumn{3}{|c|}{ Academic qualification } \\
\hline O'level & 16 & 7.3 \\
\hline NCE & 3 & 1.4 \\
\hline Diploma & 21 & 9.6 \\
\hline OND & 24 & 11.0 \\
\hline HND & 26 & 11.9 \\
\hline Bachelor's Degree & 22 & 10 \\
\hline Master's Degree & 31 & 14.1 \\
\hline $\mathrm{PhD}$ & 76 & 34.7 \\
\hline
\end{tabular}

among the university staff members. Table 1 showed that 133 male $(60.7 \%)$ and 86 female $(39.3 \%)$ were involved in the study, which indicated that more male participated in the study than their female counterparts. The nonteaching staff of the university voluntarily participated more in the study than the teaching staff. The majority of the respondents for the study were highly educated with $34.2 \%$ having obtained $\mathrm{PhD}, 14.2 \%$ Masters' degree, $10.0 \%$ Bachelors' degree, $11.9 \%$ HND, $11.0 \%$ OND,
9.6\% Diploma, NCE 1.4\% and O'level 7.3\%.

Table 2 showed that the chi-square analysis on exericse participation and healthy aging was significant. $\left(X_{\mathrm{Cal}}^{2}=204.05, X_{\mathrm{obs}}^{2}=32.67, \mathrm{df}=21\right.$, $\mathrm{P}>0.05)$. However, the table revealed that more than $60 \%$ of the respondents sometimes or do not engage in sporting activities for recreation while more than $60 \%$ walk a moderate distance for general body fitness. More than $50 \%$ of the resondents sometimes or do not do stretching 
78 Gbenga and Babalola

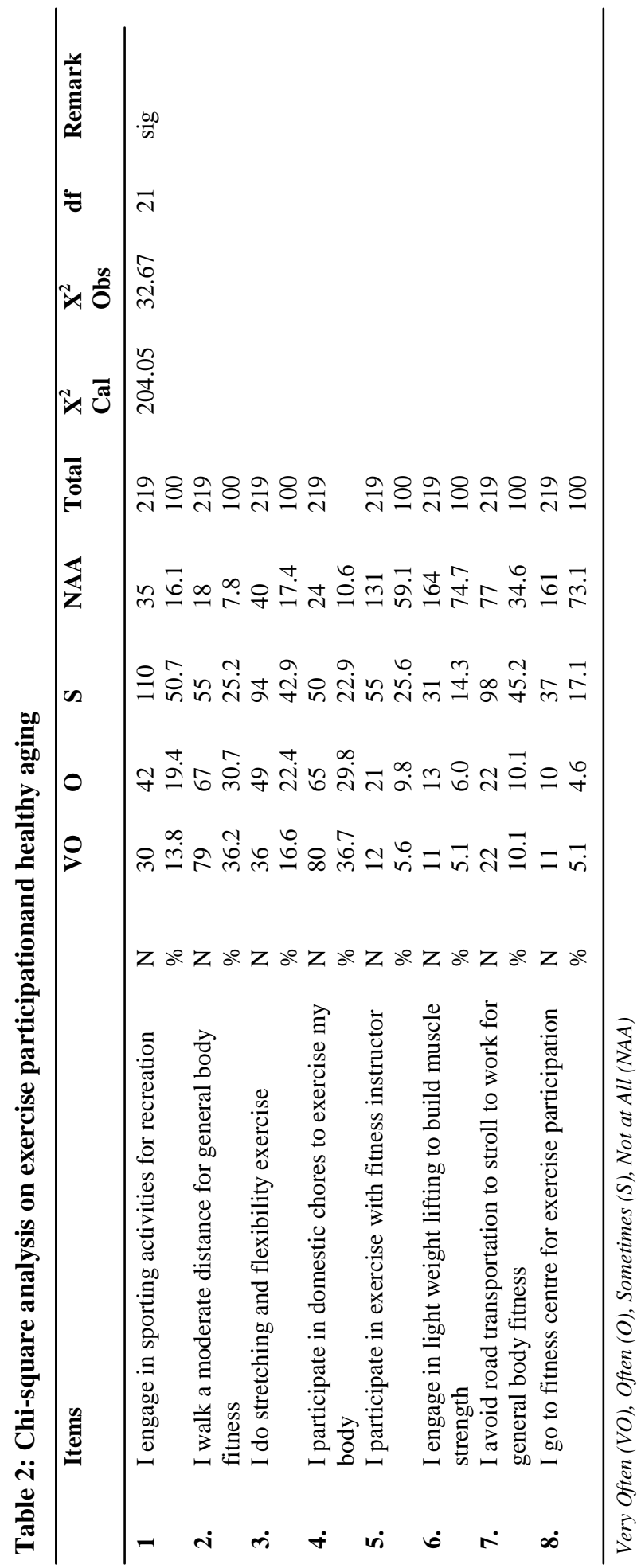

Journal of Science and Technology @ C KNUST December 2016 


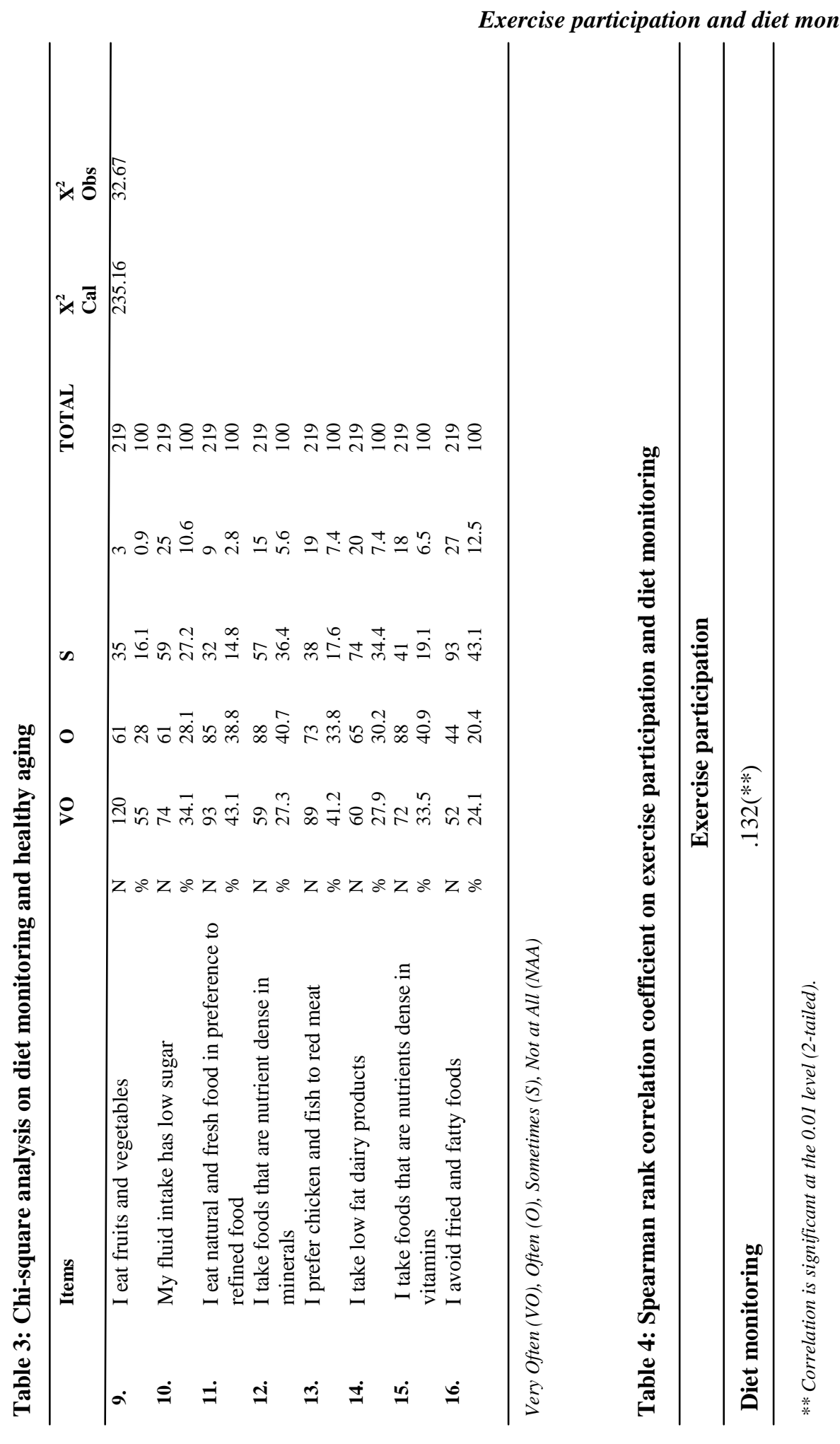

Journal of Science and Technology @ C KNUST December 2016 


\section{Gbenga and Babalola}

and flexibility exercise while more than $60 \%$ participate in domestic chores to exercise the body. More than $80 \%$ of the respondents sometimes or do not participate in exercise with fitness instructor or engage in light weightlifting to build muscle strength. More than $70 \%$ sometimes or do not avoid road transportation to stroll to work for general body fitness and sometimes or do not go to fitness centre for exercise participation. This study disagreed with Oyeyemi et al, (2013) in their recent study which reported that $68.6 \%$ of Nigerian adults living in a metropolitan city in Northern Nigeria were sufficiently active. Their conclusion of physical activity prevalence may be due to different socio-demographic characteristics and lifestyle among the groups studied, as well as differences in the definition of physical inactivity and the tools used to measure physical activity.

Modern life has in a way, negatively influenced physical activity behaviour in this present day which has led to high increase in sedentary lifestyle (Okeneye, 2002). Almost $80 \%$ of the respondents are from $\mathrm{HND}$ to $\mathrm{PhD}$ category of educational status, with assumed level of awareness and participation in healthy physical activity and exercise. According to Wilson (2002), academic qualification is a major determinant for motivation in physical activity but the result of this study contradict this submission. Working condition and other related factors may be responsible for this differences.

According to Haastrup and Adeogun (2005), regular physical activity has been found to promote the prevention and maintenance of weight gain and weight loss, when combined with diet, better cardio respiratory and muscular fitness, fall prevention, and better cognitive function in older adults. A systematic review showed that adults' leisure-time physical activity, including sports participation, has increased in five highincome countries in the past 20-30 years (Knuth and Hallal, 2009). Amongst the health benefits of exercise participation, Karmisholt and Gotzesche (2005) noted that participation in physical activity and exercise prolongs life and prevents disease if continues throughout life. Table 3 on chi-square analysis of the level of diet monitoring and healthy aging revealed that more than $80 \%$ of the respondents for the study eat fruits and vegetables very often or often while more than $50 \%$ consume fluids with low sugar. More than $80 \%$ of the population eat natural and fresh food very often in preference to refined food. More than $60 \%$ of the respondents often take food that are nutrient densed in minerals and more than $70 \%$ prefer chicken and fish to red meat. More than $60 \%$ of the respondents take low fat dairy products and more than $70 \%$ take food that are nutrient dense in vitamin. Only less than 50\% of the respondent avoid fried and fatty foods. The Chi-square goodness of fit calculated was significant $\left(X_{\text {cal }}^{2}=235.16, X^{2}{ }_{\text {obs }}=32.67, \mathrm{df}=21\right.$, $\mathrm{P}>0.05$ ). This result reveals high level of diet monitoring among respondents for the study which is in contrast to the exercise participation.

This was further confirmed by the very weak positive correlation coefficient $(\mathrm{r}=.132)$ between exercise participation and diet monitoring. This result showed an alarming concern on the attitude to exercise and diet. Stefanick et al. (1998) found that a cholesterol lowering diet alone failed to lower LDL cholesterol levels in subjects with high-risk lipoprotein levels who did not engage in aerobic exercise. For many debilitating conditions, both an inadequate diet and lack of physical activity may be risk factors (Jaiyesimi, 2009). The promotion of low to moderate exercise and dietary changes have been known to be beneficial in both general conditions and specific diseases in the elderly. Roberts and Marvin (2011) reported in their study that most adults are aware of the importance of healthy eating and the need for diet monitoring.

\section{CONCLUSION}

Exercise participation and diet monitoring are closely related to living a healthy lifestyle with 
Exercise participation and diet monitoring ... 81

satisfactory life-work growing productivity level. The study revealed that exercise participation should be considered alongside diet monitoring in pursuit of healthy aging and lifestyle. In spite of the work engagement, working condition and adopted lifestyle of university staff members, negligent towards healthy living with exercise and diet should not be tolerated.

\section{RECOMMENDATION}

It is therefore recommended that the host community (higher institution of learning) of this age categories should intensify efforts on campaign and policy to encourage healthy lifestyle through active living and proper diet consumption. Facilities for sports and fitness should be provided and walk to office campaign should be promoted in the community. Jaiyesimi (2015) recommended that with a well-coordinated and supervised workplace physical activity programme, workers can be physically active while in their workplaces, and after work.

\section{REFERENCES}

Abubakari A. R. and Bhopal, R. S. (2008). Systematic review on the prevalence of diabetes, overweight/obesity and physical inactivity in Ghanaians and Nigerians. Public Health, 122:173-182.

Abubakari, A. R., Lauder, W., Jones, M. C, Kirk. A., Agyemang, C. and Bhopal, R. S. (2009). Prevalence and time trends in diabetes andphysical inactivity among adult West African populations:the epidemic has arrived. Public Health, 123(9):602-614

Brian, W.W., Tainya, C. C., Collen, N. N. and Jeannine, S. S. (2008). National Centre for Health Statistics Early release of selected estimates based on data from the 2008 National Health Interview Survey. http:// www. cdc.gov/nchs/data/nhis. Accessed on August 26th, 2011

Frank, L. K, Heraclides, A., Danquah, I., BeduAddo, G., Mockenhaupt, F.P. and Schulze
M. B. (2012). Measures of general and central obesity and risk of type 2 diabetes in a Ghanaian population. Tropical Medicine International Health. 18(2):141-51

Hakim, A. A., Petrovitch, H., Burchfiel, C. M., Ross, G. W., Rodriguez, B. L., White, L. R., Yano, K., Curb,J. D. and Abbott, R. D. (1998). Effects of walking on mortality among nonsmoking retired men. New England Journal of Medicine, 338: 94-99.

Haastrup, E. A. and Adeogun, J. O. (2005). Personal health and physical fitness. Lagos. Tact Prints. Pg 6.

Jaiyesimi, B. G. (2009). Survey of the combination of exercise participation and proper diet as anti-aging strategy preference among the members of staff of the University of Ibadan. Unpublished Bachelor of Education project. University of Ibadan. Ibadan, Nigeria.

Jaiyesimi, B. G. (2015). Creating synergistic approach to combat lifestyle related diseases and improved quality of life through workplace physical activity and wellness intervention program. Agidigbo: ABUAD Journal of the Humanities, 3(1): 85-92.

Jeste, D.V., Depp, C. A. and Vahia, I. V. (2010). Successful cognitive and emotional aging. World Psychiatry. 9 (2):78-84.

Karmisholt, K. and Gotzesche, P. C. (2005). Physical activity for secondary prevention of diseases. Systemic review of randomized clinical trials. Danish Medical Bulletin, 52 (2): 90-94.

Knuth, A. G. and Hallal, P. C. (2009). T emporal trends in physical activity: a systematic review. Journal of Physical Activity and Health, 6: 548-559.

Monteiro, C. A,. Conde, W. L., Matsudo, S. M., Matsudo, V. R., Bonsenor, I. M. and Lotufo P. A. (2003). A descriptive epidemiology of 
leisure-time physical activity in Brazil, 1996 -1997. Revista Panamericana Salud Publica, $14: 246-254$

National Centre for Chronic Disease Prevention and Health Promotion (2011). Helping people to live long and productive lives and enjoy a good quality of life at a glance, Div. of Adult and Community Health. https:// stacks.cdc.gov/view/cdc/22022. Accessed August 16, 2011.

Okeneye, R. E. (2002). Regular exercise and individual's health. Nigerian Journal of Physical Health Education and Recreation (NIJHER), 2:5-10.

Oyeyemi, A. L, Oyeyemi, A.Y., Jidda, Z. A. and Babagana, F. (2013). Prevalence of physical activity among a d u $1 \mathrm{ts}$ in a Metropolitan Nigerian city: A cross-sectional study. Journal of Epidemiology, 23:169177.

Roberts, K. and Marvin, K. (2011). Knowledge and attitudes towards healthy eating and physical activity: what the data tell us. Oxford: National Obesity Observatory. http://
W w w. noo.org.u k/ u p load a / d o c / vid_11171_Attitudes.pdf. Accessed January 11,2012

Stefanick, M. L., Mackey, S., Sheehan, M, Ellsworth, N., Haskall, W. L and Wood, P. D (1998). Effects of diet and exercise in men and postmenopausal women with low levels of HDL cholesterol and high levels of LDL cholesterol. New England. Journal of Medicine, 339: 12-20.

U.S. Department of Health and Human Services. (2008). Physical Activity Guidelines Advisory Committee. Report of the Physical Activity Guidelines advisory Committee, Washington (DC).

World Health Organization. (2006). Global strategy on diet, physical activity and health: A framework to monitor and evaluate implementation. Geneva: WHO.

Wilson, T. C. (2002). Towards improving Nigeria performance in international sports competitions. Journal of the National Institute for Sports, 1(1): 1-8. 